\title{
Effect of diabetes and diabetes complications on hand dexterity and quality of life - a quantitative study
}

\author{
Jolanta Lewko', Elwira Sadowska², Regina Sierżantowicz ${ }^{3}$, Karolina Lewko ${ }^{4}$, \\ Cecylia Regina Łukaszuk ${ }^{1}$ \\ ${ }^{1}$ Department of Integrated Medical Care, Medical University, Bialystok, Poland \\ ${ }^{2}$ School of Medical Science, Bialystok, Poland \\ ${ }^{3}$ Department of Surgical Nursing, Medical University, Bialystok, Poland \\ ${ }^{4}$ Faculty of Medicine with the Division of Dentistry and Division of Medical Education in English, Medical University, \\ Bialystok, Poland
}

\begin{abstract}
Lewko J, Sadowska E, Sierżantowicz R, Lewko K, Łukaszuk C. R. Effect of diabetes and diabetes complications on hand dexterity and quality of life - a quantitative study. Pre-Clin Clin Res. 2019; 13(2): 61-66. doi: 10.26444/jpccr/109010
\end{abstract}

\section{Abstract}

Introduction. Diabetes and diabetes complications can cause many symptoms impairing the patient's mobility and cause difficulties in performing daily activities.

Objective. The aim of the study was to assess the effect of diabetes and diabetes complications on hand dexterity and quality of life in a group of patients in their place of residence.

Materials and Method. The studied group consisted of 100 people with diabetes - 47 women (47\%) and 53 men (53\%). The respondents were patients at the Non-Public Health Care Centre of Environmental and Family Nursing in Bialystok, north-east Poland. The study used questionnaires pertaining to disabilities of the upper limbs: QuickDASH, and SF-36v2 Health Survey.

Results. Significant, inversely proportional correlations between the results of the QuickDASH and the general results of the SF-36v2 Health Survey were shown, which means that the correlation coefficient $r=-0.847$ and the quality of life results in PCS (physical component summery) and MCS (mental component summery), the correlation coefficients were $r=-0.489$ and $r=-0.842$, respectively. The greater the disability in hand dexterity was, the lower the quality of life in the physical and mental health domains. Existence of one complication did not significantly affect the outcome of the QuickDASH, while the occurrence of two or three complications had a significant impact on this result $(p<0.05)$.

Conclusions. Patients' quality of life declines significantly when two or more complications occur, both in the physical and mental domains. Older age groups reported worse sensing within the hands. Patients with comorbidities assessed their quality of life considerably worse.

\section{Key words}

diabetes complications, hand dexterity, quality of life

\section{INTRODUCTION}

The most common chronic complication of diabetes is diabetic neuropathy. At the time of diagnosis, $8-10 \%$ of patients suffer from diabetic neuropathy and this percentage increases with the duration of diabetes, and after 25 years affects $45-60 \%$ of patients. The largest number of patients are in the group with the least metabolic balance [1].

Szczyrba et al. [2] cited a study conducted in the United Kingdom, where the incidence of diabetic neuropathy is estimated at $28.5 \%$, on average: $22.7 \%$ with insulin-dependent diabetes and $32.1 \%$ with non-insulin dependent diabetes. However, when analyzing the patients' age, it turned out that in the 20-29 age group it was 5\% and in the 70-79 age group $-44.2 \%$ with diabetic neuropathy. The percentage of patients increases with the duration of diabetes, in patients treated for less than 5 years $-20.8 \%$, more than 10 years $36.8 \%$. P. Rajewski et al. [3] also cites the same study, while

Address for correspondence: Jolanta Lewko, Department of Integrated Medical Care, Medical University, Bialystok, Poland

E-mail: jola.lewko@wp.pl

Received: 18 March 20119; accepted: 27 April 2019; first published: 30 May 2019 also presenting data from Spain, where polyneuropathy was found in $14 \%$ of patients suffering less than 5 years and in $44 \%$ of patients with diabetes lasting over 30 years.

The mean prevalence of diabetic neuropathy is estimated at $1-90 \%$, such large discrepancies result from the application of various diagnostic criteria, test methods, and taking into account the varying clinical pictures of polyneuropathy [4].

Most often, complications involving the musculoskeletal system involve the lower limbs (including diabetic foot), but may also affect the hands [5]. They may be the result of new changes in the collagen structure, the main component of tendons, which is connected with glucose. The result of changes in the joints is persistent pain, impairing mobility [6].

\section{OBJECTIVE}

The aim of the study was to assess the effect of diabetes and diabetes complications on hand dexterity, and quality of life in a group of patients in their place of residence. 


\section{MATERIALS AND METHODS}

The studied group consisted of 100 people with diabetes, aged 19-89 years (mean age 60 years) - 47 women (47\%) and 53 men (53\%). The respondents were patients at the Non-Public Health Care Centre of Environmental and Family Nursing in Bialystok. The research method was a diagnostic opinion poll using questionnaires - a questionnaire pertaining to disabilities of the upper limbs, QuickDASH, and the SF-36v2 Health Survey.

The QuickDASH was developed to assess the ability of the respondent to perform certain daily activities, and the presence of such symptoms as pain and tingling of the arm, shoulder or hand. The questionnaire contains 11 questions, with answers on a five-point Likert-type scale, where the lowest value means no restrictions or lack of a symptom, and the highest means impossibility to perform an activity or a severe symptom. An integral part of the questionnaire is two optional modules, "Work" and "Sport/Playing an instrument." For the purpose of the conducted research, the optional module "Work" was used [7]. Calculations were performed in accordance with the recommendations of the Institute for Work \& Health [8].

Quality of life (HRQoL) was measured using the SF-36v2 Health Survey, consisting of eight subscales assessing the following dimensions of quality of life: physical functioning (PF), social functioning (SF), limitation of fulfilling social roles due to physical causes (physical role functioning $\mathrm{RP}$ ), limitation of fulfilling social roles due to mental causes (emotional role functioning - RE), bodily pain (BP), general health $(\mathrm{GH})$, vitality (VT), and mental health $(\mathrm{MH})$. The construction of the SF-36v2 allows to isolate the calculation of aggregate results in 2 dimensions: physical functioning (physical component summary - PCS) and mental functioning (mental component summary - MCS). The scale has good psychometric characteristics [9].

Approval of the Bioethics Committee of the Medical University of Bialystok was obtained for the study (No. R-I002/545/2015).

Statistical analysis. Statistical analysis of the results was performed with the STATISTICA 12 programme, the Kruskal-Wallis ANOVA test was used to examine relationships between variables. The Spearman rank correlation coefficient was used to determine relationships between variables. Statistical significance was set at $\mathrm{p}<0.05$.

\section{RESULTS}

The age of the respondents ranged from 19-89 years (average 60 years). They were categorized in the six age groups: I - up to 24-years-old, II - 25-34 y.o., III - 35-44, IV - 45-54, V $55-64$, and VI $-\geq 65$ y.o. BMI values in the examined group are presented in Table 1. In the group of respondents, type II diabetes dominated - 76 out of 100 people (76\%), while 24 had type I diabetes (24\%). A very important factor affecting a patient's life and the possibility of complications is the duration of diabetes, which was another problem addressed in the survey. The respondents' age ranged from 2-56 years (average 24.85 years). They were divided into 6 groups depending on the disease duration: Group I $-\leq 9$ years, II -
Table 1. Characteristics of the study group

\begin{tabular}{lcc}
\hline & $\mathrm{n}$ & $\%$ \\
\hline Females & 48 & $48 \%$ \\
\hline Males & 52 & $52 \%$ \\
\hline UnI & & \\
\hline Correct (18,5-24,99) & 3 & $3 \%$ \\
\hline Obesity I degree & 33 & $33 \%$ \\
\hline Obesity II degree & 19 & $19 \%$ \\
\hline Obesity III degree & 4 & $4 \%$ \\
\hline Type I diabetes & 4 & $4 \%$ \\
\hline Type II diabetes & 26 & $26 \%$ \\
\hline Average age (years) & 73 & $73 \%$ \\
\hline Average duration of disease (years) & & $60.2+/-20.7$ \\
\hline
\end{tabular}

10-19 years, III - 20-29 years, IV - 30-39 years, V - 40-49 years, and VI $-\geq 50$ years.

The largest group was composed of patients from group I $(36 \% ; n=36)$, patients from group II $(33 \% ; n=33)$ were a slightly smaller group. There were $14(14 \%)$ people with diabetes aged 20-29 years (group III), 9 (9\%) patients in group IV (disease duration 30-39 years), 7 (7\%) in group V. The smallest group was treated for diabetes lasting over 50 years $(1 \% ; n=1)$.

In the case of $12(12 \%)$ people, treatment consisted of oral preparations. Whereas, insulin was received by a much larger group of subjects -88 people (88\%). Combination therapy was not used in anyone from the analyzed group.

A very important issue, especially in more severe cases of diabetes, is sensing within the hands. This problem occurs in people who professionally do manual activities (seamstress, cashier, hairdresser). Hand dexterity is a prerequisite for performing basic tasks at work. Often, neuropathy is a complication of diabetes that limits or prevents the performance of professional activities.

Respondents' answers indicate that $23 \%$ of them assessed sensing within the hands as good and $2 \%$ as very good. A total of $16 \%$ of respondents reported fairly good sensing. Thus, less than half of the respondents (41\%) could perform their activities without obstructions. However, the vast majority of the analyzed group (59\%), assessed sensing within the hands as bad (45\%) and very bad (14\%). These people encountered difficulties performing their professional activities.

Serious health problems of patients with diabetes are late complications that may lead to disability and premature death. Analysis of the questionnaires showed that as many as $84 \%$ of the respondents had complications due to diabetes: 30 people had 1 complication, 42 had 2 , and 12 patients had 3 . The most common complication was diabetic neuropathy, which affected 61 people. A similar number of patients had retinopathy (47 people) and diabetic foot (42). Only 1 respondent indicated diabetic nephropathy as a complication.

Average values for 2 dimensions of SF36v2 were: PCS (physical component summary) mean 40.5 CI 95\% (39.441.6), MCS 38.5 CI 95\% (37.6-39.4) and for QuickDASH 49.7 CI 95\% (43.4-56.1) (Tab. 2). Analysis of Spearman rank correlation showed a significant directly proportional correlation between the quality of life results in the physical component summary (PCS) and the quality of life in MCS (mental component summery), the health dimension; 
Table 2. Descriptive statistics for physical component summary, mental component summary (SF-36v2) and QuickDASH ( $\mathrm{N}=100)$

\begin{tabular}{lccccccc}
\hline & $\begin{array}{c}\text { Mean } \\
(\mathrm{Cl} 95 \%)\end{array}$ & SD & Min. & Max. & $\mathrm{C}_{25}$ & Med. & $\mathrm{C}_{75}$ \\
\hline PCS & $\begin{array}{c}40.5 \\
(39.4-41.6)\end{array}$ & 5.6 & 24.7 & 57.2 & 36.5 & 39.2 & 44.7 \\
\hline MCS & $\begin{array}{c}38.5 \\
(37.6-39.4)\end{array}$ & 4.5 & 26.8 & 47.5 & 35.7 & 38.2 & 41.2 \\
\hline QD & $\begin{array}{c}49.7 \\
(43.4-56.1)\end{array}$ & 32.0 & 0.0 & 97.7 & 20.4 & 53.4 & 77.3 \\
\hline
\end{tabular}

$\mathrm{Cl}$ - confidence interval; $\mathrm{CS}$ - physical component summary; $\mathrm{MCS}$ - mental component summary QD - QuickDASH

correlation coefficient $\mathrm{r}=0.569$; significant directly proportional correlation of physical well-being (PCS) with the overall score - correlation coefficient $r=0.688$, and significant directly proportional correlation of mental wellbeing (MCS) with the overall score - correlation coefficient $r=0.942$. Dependencies were shown between the results of the QuickDASH and the general results of the SF-36v2 Health Survey, which means that the correlation coefficient $r=-0.847$ and the quality of life results in the physical PCS and the MCS: the correlation coefficients were $r=-0.489$ and $r=-0.842$, respectively. This means that the greater the disability in hand dexterity (Index QuickDASH), the lower the quality of life (SF-36v2) in the physical and mental health domains.

Analysis of the results revealed that one complication did not significantly affect the quality of life, compared with the group of patients without complications. There were no significant differences in the quality of life between 2 complications compared with 3 . A statistically significant difference was found between the groups with 0 and 1 complication and 2 and 3 complications $(p<0.05)$. It was found that the presence of 2 or more complications significantly affected the patients' physical well-being. One complication did not negatively affect assessment of quality of life (Fig. 2).

Statistical analysis also included the effect of the number of complications on the patients' quality of life in the mental health dimension (MCS). There were statistically significant differences in the comparison of groups without and with one complication with groups with 2 and 3 complications. No complications and one complication did not affect the respondents' mental well-being. The existence of 2 and 3 complications significantly affected the quality of life in the mental health dimension $(\mathrm{p}<0.05)$.

The respondents' complications were also analyzed in relation to the overall score on the QuickDASH, obtaining the same results as in the case of the SF-36v2. Analysis showed a close correlation between the 2 questionnaires (Fig. 3). In the current study it was found that the existence of one complication did not significantly affect the outcome of the QuickDASH, while the occurrence of 2 or 3 complications had a significant impact on this result $(\mathrm{p}<0.05)$.

The next variable examined was sensing within the hands as assessed by the respondents. Respondents were divided into 2 groups: Group I - with poor or very poor sensing; and group II - with good, very good and fairly good sensing. Both groups were analyzed in terms of the overall score on the SF-36v2, showing a statistically significant difference between these groups $(\mathrm{p}<0.05)$. Patients from Group I had a significantly smaller overall score on the SF-36v2.

Both groups were also compared in terms of quality of life in the PCS and the MCS dimensions. The conducted

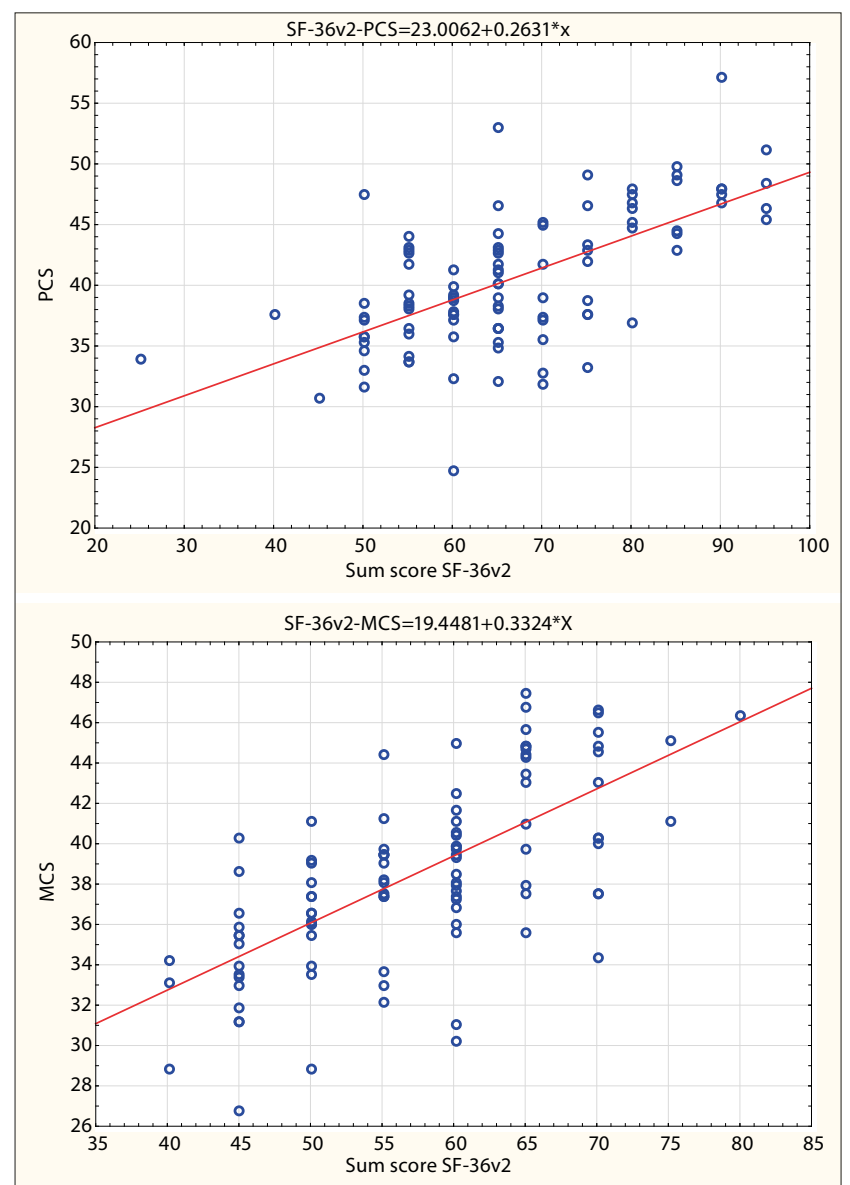

Figure 1. Correlations between physical and mental health in relation to the SF-36v2

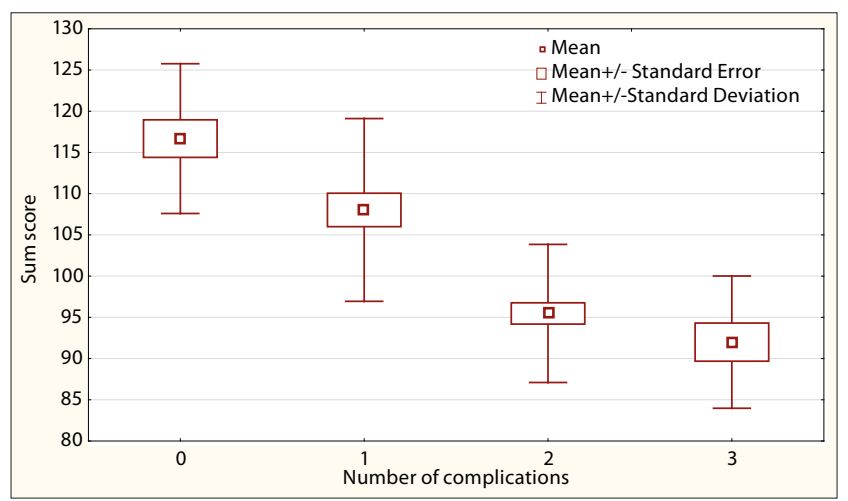

Figure 2. Effect of the number of complications on the quality of life (SF-36v2)

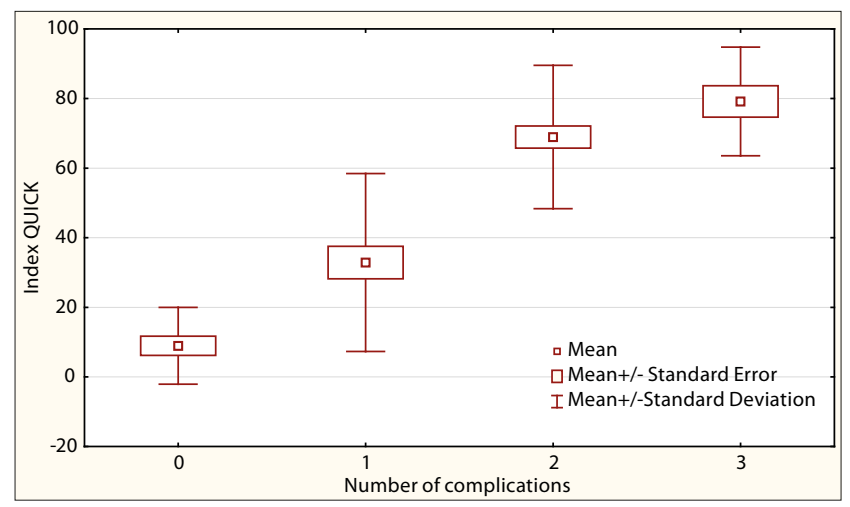

Figure 3. Effect of the number of complications on QuickDASH results 
analysis showed a significant difference in both cases $(p<0.05)$. Similarly, patients in Group I reported worse results in quality of life in the PCS and the MCS. The current study also attempted to compare the results of the handsensing quality in individual groups with the overall score on the QuickDASH. There was also a statistically significant difference, patients from Group II obtained lower scores on the QuickDASH questionnaire.

Next, the same 2 groups of patients, those with poor and good sensing within the hands, were compared in relation to the duration of diabetes. However, results of statistical analysis showed no significant differences.

Analysis of the patients divided into the original age groups showed that patients in groups 1-4 (9-54 y.o.) and 5-6 (55-89 y.o.) gave homogeneous responses regarding the assessment of sensing within the hands. This justifies the adoption of a new division into only 2 of the mentioned age groups, in which a significant difference in the scope of the examined parameter was demonstrated.

Statistical analysis showed a significant difference between individual age groups and the quality of sensing within the hands. Older age groups reported worse sensing within the hands. It was found that the number of diabetes complications was statistically significantly different in groups with and without disorders of hand sensing (Fig. 4). More often, the complications concerned patients who had an increase in disorders of sensing within the hands. An attempt was also made to assess the quality of life of patients with comorbidities (i.e. cardiovascular diseases). It was found that this group assessed their quality of life as significantly worse, both in the physical (PCS) and mental (MCS) dimensions, than the comorbidity-free group.

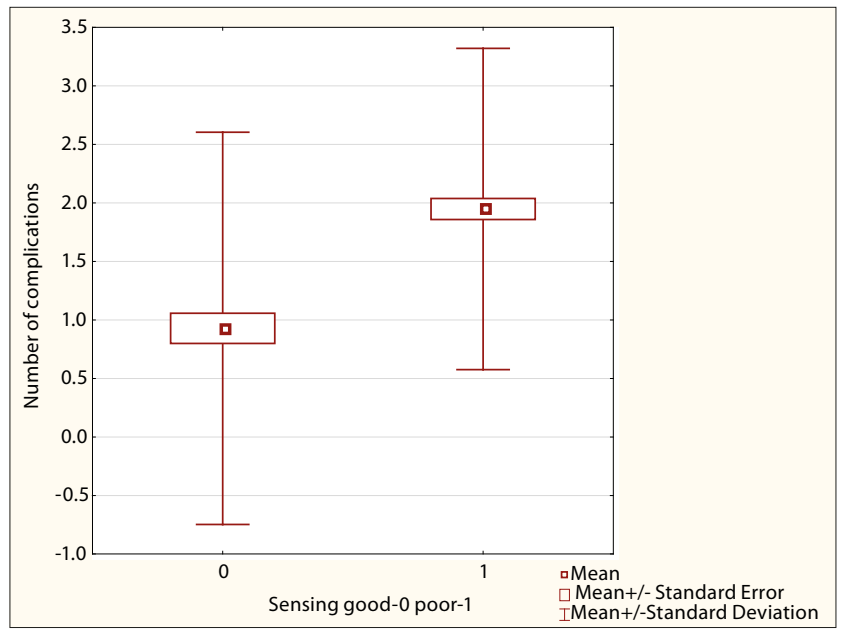

Figure 4. Results of analysis of sensing within the hands in relation to the number of diabetes complications

\section{DISCUSSION}

All diseases are disruptive and have an adverse effect on life and functioning. Chronic disease, such as diabetes, places a long-term strain on a person's life and may pose a significant risk to physical, social, and emotional development $[10,11]$.

Diabetes is diagnosed more and more often in modern societies, and there is a progressive rise in the incidence of diabetes worldwide. The risk of diabetes occurrence increases with population growth, the aging of societies, especially in Europe, the effects of industrialization, but also, and perhaps most importantly, the obesity epidemic, as indicated by Bergman and others $[12,13]$. It is estimated that currently $6 \%-9 \%$ of the adult population suffer from diabetes. Rapid economic development and lifestyle changes mean that in China, for example, the incidence of diabetes will increase by as much as $30 \%$ within the next 30 years. Data published in 2006 by the International Diabetes Federation on the prevalence of diabetes in Poland show that there are 9.1\% of people aged 20-79 struggling with this disease. Forecasts predict that by 2025 this percentage will increase to $11 \%$ [11].

The presented study conducted on a group of 100 people with diabetes shows that as many as $64 \%$ of respondents are overweight or obese, of whom $4 \%$ have morbid obesity (BMI >40).

At the beginning of the 1990s, the concept of health-related quality of life (HRQOL) was introduced, which is closely related to the definition of health adopted by the World Health Organization (WHO). It allows observation of a patient in 3 dimensions: physical, psychological, and social. The WHO defines quality of life as a comprehensive way to assess an individual's physical and emotional health, as well as his/her relationship with the environment. The term "quality of life" should be considered in a multifaceted manner, it should also take into account all aspects of life affected by the disease. Focusing on these areas is a prerequisite for success in the treatment of diabetes [14].

Diabetes is a chronic disease, often with various complications modifying the patient's life in each of these aspects. Both the disease itself and its complications have a major impact on quality of life [15]. Kurpas showed that the occurrence of diabetes complications lowers the quality of life in every studied domain, having the strongest impact on the physical and mental dimensions [16].

The current study shows that $84 \%$ of respondents had at least one complication which confirms the literature data. Kurpas et al. [16] report $81 \%$ of patients with complications of diabetes, Chien-Ju et al. [17] confirm that $58-82 \%$ of patients with diabetes had neuropathy confirmed by electrophysiologic tests. Neuropathy within the hands was reported by as many as $92.8 \%$ of the participants.

There are many studies in the world literature devoted to the issue of diabetic foot and its negative impact on the quality of life of patients. The literature devotes considerably less attention to the study of relationships regarding hand dexterity in the course of diabetes. Papanas and Maltezos [18] believe similarly in their work on the subject. According to the authors, the problem of diabetes complications related to the hands was widely discussed in the 1970s and 1980s. Currently, the topic has been forgotten.

The presented study is a review paper with the aim of discussing hand pathology that may be of clinical significance in patients with diabetes. The authors disagree with many researchers who use the term "diabetic hand" for only 3 of the many complications of diabetes. The definition of "diabetic hand" they propose is: "musculoskeletal symptoms (namely limited joint mobility, Dupuytren's contracture and trigger finger) in patients with diabetes, usually associated with long-term diabetes, poor metabolic control and the presence of microvascular complications" [18].

Further research in this direction was carried out by ChienJu Yang et al. [17] who confirmed that the quality of life of 
patients with polyneuropathy was significantly lower than patients with mononeuropathy. Patients without neuropathy had the highest quality of life.

These results are in concordance with the current study in which the overall quality of life in patients without and with one complication was much better than in patients with 2 or more complications. The same group of patients also assessed their physical and mental well-being as being worse.

Diabetic neuropathy seems to have the most negative impact on the quality of life of patients with diabetes than any other complication. A very important indicator in diabetes development, especially in more severe cases, is sensing within the hands. This problem occurs in people who professionally perform manual activities (seamstress, cashier, hairdresser). Hand dexterity is a prerequisite for carrying out basic tasks at work. Often, neuropathy is a complication of diabetes that limits or prevents the performance of professional activities. The beginning of neuropathy and early symptom occurrence are usually very mild, and patients compensate the slight discomfort in the functioning of their hands in daily activities by gradual acclimatization.

In the current study, 59\% of the respondents indicated poor and very poor sensing within the hands. Only $2 \%$ had very good results. The rest had good (23\%) and fairly good (16\%) sensing within the hands. The study also showed that diabetes duration did not have a significant impact on the occurrence of hand dysfunctions, as in the study by Lewko et al. [19], a relationship that was not confirmed by Gamstedt et al. [20].

Padua et al. [21] showed that disruptions in the functioning of peripheral nerves reduced the quality of life in the physical, but not in the mental, dimension. The study by Lewko et al. [19] did not confirm this fact. Similar to the current study, it did not show that the quality of physical or mental life was significantly affected by hand neuropathy.

The physical dimension of quality of life is also affected by comorbidities. The simultaneous occurrence of other diseases causes the patients to assess their quality of life as much worse than those who do not have comorbidities. Fal et al. [22] showed that cardiovascular diseases lowered the quality of life the most (in group A, treated with insulin, heart failure; in group B, ischemic heart disease). Similar results were presented by Kurpas et al. [16]; 56\% of study participants had cardiovascular diseases. Patients with complications (57\%) in this study were satisfied with their quality of life, but only $23 \%$ with their dstate of health. The highest percentage of respondents (47\%) was neither satisfied nor dissatisfied with their health. In the presented study, the diabetic group with comorbidities assessed their quality of life significantly worse than the group without comorbidities $(\mathrm{p}<0.05) ; 56 \%$ of the study participants had cardiovascular diseases.

One way to improve the quality of life of patients suffering from diabetes is adequate health education and constant glycaemic control. Acquiring knowledge about diabetes results in a reduction in the sense of anxiety and disability caused by the disease, and a decrease in lifestyle restrictions. Properly conducted training broadens the patient's knowledge and skills, affecting the sense of independence and self-reliance, reducing fears and anxiety. It is important that in addition to the doctor and nurse, the team of educators should include a psychologist, whom the patient will be able to sk for help and who will teach how to cope with the disease, thereby raising the level of mental quality of life.
The limitations of this study were the small number of respondents and the authors' lack of knowledge about hand dexterity among hospitalized patients.

\section{CONCLUSIONS}

The obtained results justify the statement that the 2 questionnaires, the QuickDASH on upper limb disabilities and the SF-36v2, are equivalent. A patient's well-being in the mental domain depends in direct proportion on physical wellbeing. Quality of life declines significantly when 2 or more complications occur. This applies to both the physical and the mental domains. Older age groups reported worse sensing within the hands. The number of diabetes complications was statistically significantly different in groups with and without sensing hand disorders. The group of patients with comorbidities assessed their quality of life as significantly worse, both in the physical and mental dimensions.

\section{REFERENCES}

1. Sękowska A, Malec-Milewska M. Zastosowanie duloksetyny w leczeniu bólu neuropatycznego - bolesna polineuropatia cukrzycowa. Neuroedu. pl. Serwis Edukacyjny Polskiego Towarzystwa Neurologicznego 2016, s. $1-7$.

2.Szczyrba S, Kozera G, Bieniaszewski L, Nyka WM. Neuropatia cukrzycowa - patogeneza, rozpoznawanie, zapobieganie, leczenie. Forum Medycyny Rodzinnej 2010; 4(5): 339-355.

3. Rajewski P, Rajewski P. Etiologia i patogeneza neuropatii cukrzycowej w świetle aktualnych badań. Przegląd Kardiodiabetologiczny 2007; 2(4): 267-272.

4. Witek P. Algorytmy postępowania w neuropatii cukrzycowej. Diabetologia Praktyczna 2009; 10(5): 186-195.

5. Kim RP, Edelman SV, Kim DD. Musculoskeletal Complications of Diabetes Mellitus. Clin Diabet. 2001: 19(3): 132-135.

6. Jude EB, Jacob K. Managing painful neuropathy in diabetes. Pol Arch Med Wewn 2008, 118(5): 1-2.

7. Golicki D, Krzysiak M, Strzelczyk P. Translation and cultural adaptation of the Polish version of the Disabilities of the Arm, Shoulder and Hand (DASH) and QuickDASH questionnaires. Ortop Traumatol Rehabil 2014; 16(4): 387-95. doi: 10.5604/15093492.1119616.

8. Institute for Work \&Health: Kwestionariusz QuickDASH, 2006.

9. Ware JE, Kosiński M, Dewey JE. How to score Version 2 of the SF-36 Health Survey. Lincoln, RI: QualityMetric Incorporated; 2000.

10. Czechura J. Terapia ciągły podskórnym wlewem insuliny $\mathrm{z}$ zastosowaniem pomp insulinowych a jakość życia pacjentów. Przegląd Medyczny Uniwersytetu Rzeszowskiego i Narodowego i Narodowego Instytutu Leków w Warszawie. 2010; 4: 435-443.

11. Dąbrowska A, Jurkowska B, Nowicki G, Prystupa A, Bednarski J, Pietryka-Michałowska E. Ocena wybranych elementów psychicznej jakości życia pacjentów leczonych z powodu cukrzycy typu 2. Curr Probl Psychiatry 2012; 13(2): 128-133.

12. Bergman K, Olender K, Odrowąż-Sypniewska G. Rola otyłości i stanu zapalnego w cukrzycy typu 2 - znane fakty, nowe kontrowersje. J Lab Diagn. 2012. 48(3): 313-322.

13. Bansal V, Kalita J, Misra UK. Diabetic neuropathy. Postgrad Med J 2006; 82(964): 95-100.

14. Szybiński Z, Dziatkowiak H, Wąsikowa R, Kinalska I, Korman E, Grzywa M, Korniszewski L, Trippenbach H, Bandurska-Stankiewicz E, Pach D, Płaczkiewicz E, Ciechanowska M, Bieniarz J, Kowalska I, Stankiewicz W, Sobel-Maruniak A, Orłowska-Florek R, Staniszewski A, Symonides-Ławecka A, Dziubińska-Kolender, Kiełtyka A, Walczycka L. Wieloośrodkowe badania nad zapadalnością na cukrzycę typu 1 w grupie wiekowej 0-14 lat w Polsce w latach 1998-1999. Pol Arch Intern Med. 2001; 106:751-758.

15. Lewko J, Krajewska-Kułak E. Wielowymiarowa ocena jakości życia chorych na cukrzycę. Pol Merk Lek. 2010, 28(168): 486-489.

16. Kurpas D, Czech T, Mroczek B. Jakość życia pacjentów z cukrzycą - jakie znaczenie mają powikłania? Fam Med Prim Care Rev, 2012, 14(2): 177-181 
17. Chien-Ju Y, Hsiu-Yun H, Chieh-Hsiang L, Yen-Li C, Haw-Yen C, LiChieh K. Do we underestimate influences of diabetic mononeuropathy or polyneuropathy on hand functional performance and life quality? J Diabetes Investigation 2017; doi: 10.1111/jdi.12649.

18. Papanas N, Maltezos E. The diabetic hand: a forgotten complication? J Diabetes Complications 2010; 24(3): 154-162.

19. Lewko J, Kochanowicz J, Zarzycki W, Mariak Z, Górska M, KrajewskaKulak E. Poor hand function in diabetics. Its causes and effects on the quality of life. Saudi Med J. 2012; 33(4): 429-435.
20.Gamstedt A, Home-Glad J, Ohison C.G, Sundström M. Hand abnormalities are strongly associated with the duration of diabetes mellitus. J Intern Med 1993; 234: 189-193.

21. Padua L, Saponara C, Ghirlanda G, Aprile I, Padua R, Pauri F, Tonali P. Health-related quality of life type 1 diabetic patients and influence of periheral nerve involvement. Neuro Sci. 2001; 22: 239-245.

22. Fal AM, Jankowska B, Uchmanowicz I, Sen M, Panaszek B, Polanski J. Type 2 diabetes quality of life patients treated with insulin and oral hypoglycemic medication. Acta Diabetol. 2011; 48(3): 237-242. 